\title{
notes
}

\section{Arguings and Arguments}

\author{
Fred Johnson \\ Colorado State University
}

In [1] Spangler characterizes Fogelin's definition of "argument" in [2] as being non-teleological and claims that such a definition will not work for a course in informal logic. Spangler says: "The idea of an argument as a series of statements 'connected' in various ways leaves out of the story of argumentation its most important character, viz., the arguer and his purposes." (p. 29) What bothers me about Fogelin's discussion is that he does not leave the arguer out of his understanding of arguments. Indeed, he treats arguments and parts of arguments as if the were arguers. Fogelin says: "Sometimes the primary intention of an argument is not to establish some truth, but rather to criticize or refute an argument presented by another." (p. 103) And he says: "...they [the warranting connectives, such as 'since' and 'so'] present one or more statements as the warrant or backing for some other statement." (p. 39) Fogelin gives conflicting accounts of what an argument is. For him, arguments are both passive entities-series of statements connected in various ways-and active entitites that intend and have parts that present.

The natural response that Fogelin might make to the above charge of inconsistency is that his talk about arguments as having intentions is not to be taken literally. How boring it would be if we could not jazz up our talk and speak as if the lifeless had life! But this response seems weak to me. Granted, people who know cars may, with benefit, whimsically describe their cars as feeling ill and as wanting to go to the doctor. But would it be wise to talk in this way to someone who needs to know, but does not know, what a car is? No. And our students need to recognize arguments, but too few of them can do so.

My view is that arguments are passive, and I construe talk about arguments in this way. So, when I read the following passage I do not think that the author is saying that arguments have misconceptions, but that Holzman does. "...Professor Holzman suggests that all Soviet military forces allocated to the Far East should be excluded from comparisons of NATOWarsaw Pact military expenditures, since these forces are "irrelevant to the superpower confrontation.' There are three misconceptions in this argument: ..." (Atlantic (Nov. '83), p. 7) The argument is that "all Soviet military ... expenditures, since these forces ... confrontation." And it is by this ostensive method of definition that I think we can have the most success in helping our students recognize arguments. It may be tempting to define "argument" as an ordered pair whose first member is a set of propositions and whose second member is a proposition, but the temptation should be resisted. The basic skills that we would like our students to acquire can be acquired without entering into a discussion of realist definitions and their nominalist competitors.

Suppose we adopt this metaphysically neutral means of defining "argument". There is an objection that I think Spangler has in mind: "If that A since $B$ is an argument then it could be the case that that $A$ since $B$ is also an explanation. Suppose, for example, that Holzman thinks that his audience believes that all Soviet military ... expenditures. Then Holzman's explanation is that A since B. But arguments cannot be explanations. So we are wrong in identifying Holzman's argument." My response to this objection is that arguments can be explanations. It is arguing that cannot be explaining. We say that $\mathbf{A}$ is arguing for $\mathbf{B}$ if $\mathbf{A}$ is trying to persuade $\mathbf{C}$ to believe that $\mathbf{B}$ by asserting that $\mathbf{D}$, where $\boldsymbol{A}$ thinks that $\mathbf{C}$ does not believe that $\mathbf{B}$. And we say that $\mathbf{A}$ is explaining that $\mathbf{B}$ if $\mathbf{A}$ asserts that $\mathbf{D}$ in order to help $\mathbf{C}$ see that $\mathbf{B}$ fits (or makes sense), where $\mathbf{A}$ thinks that $\mathbf{C}$ believes that $\mathbf{B}$. Argumentation consists of activities of arguing and arguments. So Spangler is right in saying that we cannot exclude the arguer and his purposes from the study of argumentation. But he is wrong in saying that we cannot exclude the arguer and his purposes from the study of argument.

But is it not odd to say that arguing is different from explaining and to say that an argument may be an explanation? I do not think so. We say that the lawyer's activity of pleading for the defendant's life is different from the victim's activity of cursing the defendant. Yet the lawyer's plea might be the victim's curse: that he is mentally deficient. 
When we try to avoid complicating our discussion of argumentation by restricting our attention to arguments, it is inevitable that we will be forced into the inconsistent position of making arguments both passive and active. The troubles with the deductive-inductive distinction are also due to making arguments bear too much weight, as I noted in [3]. The activity of arguing is where the deductive-inductive distinction belongs. So, let us attend both to active anguings and passive arguments.

\section{References}

[1] Spangler, G. A. "Fogelin's Understanding Arguments," ILN, v.2 (1983), 27-30.

[2] Fogelin, Robert J. Understanding Arguments. 2nd ed. (New York: Harcourt Brace Jovanovich 1982.)

[3] Johnson, Fred. "Deductively-Inductively," ILN iii.1 (1980), 4-5.

Fred Johnson, Department of Philosophy, Colorado State University, Fort Collins, Colorado 80523.

\title{
Teaching Informal Logic in High School
}

\author{
Pamela Courtenay Hall
}

I'm a high school teacher with a background in philosophy, so it didn't take much to convince me of the usefulness of getting informal logic into the high school curriculum. But a recent experience has brought me from thinking "useful" to thinking "essential to the goals of education", and $l^{\prime} \mathrm{m}$ in earnest now about wanting to see the development take place soon. Here's what happened.

I was asked to fill in for a history teacher-a grade 9 lesson on "The advent of Communism in Europe". Points to be covered were "Russia at the end of WWI; the Brest-Litovsk Treaty; Kerensky; Marx and his philosophy; the Revolution". A hefty task! But there were complications on top of it: the outline promised by my instructions was nowhere to be found; all of the textbooks were being used by another class; I had 15 minutes' notice, and the period was 75 minutes long.

Informal Logic to the rescue! Here's how: (1) I involved the students in an attempt to define "communism", "totalitarianism", "socialism", "capitalism", "democracy", etc. (no dictionary in the room!), pointing out the differences between the concepts, and the difficulties involved, including those which a dictionary would not solve, in trying to give adequate definitions. (2) I read from a 1963 textbook (the only thing available) on the topic "Russia today" - the American perspective circa 1956-and asked the students to identify any distortion or selection that they noticed. (Much initial explanation required.) (3) We discussed how one might argue for communism and how one might argue against it, both from the perspective of a well-off Canadian student and from the possible perspective of a young person living in poverty. (4) We considered key terms in Marx's idea that human beings are conditioned by the economic situation they are born into, and we discussed whether these key terms were clear or vague in some troublesome way. We also discussed whether the idea operated on a full or partial consideration of what is important in a person's life.

It was fun for me, and the learning was evident in their comments and in their faces. The students found reasoning a real break from just copying notes off the board. (Yes, in spite of awareness of other methods and the many resources available, the old (easy) rote ways are still used exclusively by some teachers.) Of course, what they learned that day was not "history": by the end of class, the students had learned only a few of the details of "The Advent of Communism in Russia". But given the unusual absence of textbooks and teaching materials, they learned more than could be expected, both of the historical details and, more importantly, of how one might connect with them. 
What really sold me on informal logic in the classroom was the live realization that these kids haven't just learned, e.g. that a textbook can be slanted: they've learned what some of the tools of slanting are by name, and those who remember from one lesson (no illusions here) will detect these techniques being used in advertising, in the newspaper, in their friends' (and their own) arguments. That kind of pay-off should be the hallmark of education.

However, the history teacher who was absent that day isn't likely to adapt informal logic into his lessons any better than he adapted a variety of mèthods into his teaching approach. For anyone keen on getting informal logic into the high school curriculum, an important first step is to get informal logic into the teacher's college curriculum. Believe me, had it been offered at my Faculty of Education in 1979, it would have been one of the most valuable courses offered.

Pamela Courtenay Hall, c/o Department of Philosophy, University of Windsor, Windsor, Ontario, Canada N9B 3P4

\section{announcement}

\section{Conference on Critical Thinking Christopher Newport College April 11-12, 1985}

Report after report on what ails education in the U.S. calls for more emphasis on reasoning and critical thinking. The goal of this conference is to direct the attention of educators, humanists, and scientists to recent work on critical thinking and informal logic that might help us better address these needs.

Our speakers are nationally and internationally prominent for their original work in developing these fields. They combine classroom experience teaching critical thinking from primary school through community college to university level.

MICHAEL SCRIVEN. Author of Reasoning (1976), he is in important ways the founder of the informal logic movement as it exists today. He will point out some of the shortcomings of recent symbolic logic in dealing with arguments in ordinary language, and then indicate what is needed to do the job better.

ROBERT H. ENNIS. A leading authority on conceptualizing and testing critical thinking, he is co-author of two widely used testing instruments in the field (Cornell Critical Thinking Tests). He will elaborate and illustrate a concept of critical thinking to show us what critical thinking involves.

MATTHEW LIPMAN. Founder of the Institute for the Advancement of Philosophy for Children, he has produced such excellent teaching materials for critical thinking for children as Harry Stottlemeier's Discovery, with its outstanding Instructor's Manual. He will describe the critical thinking for children program he has devised, which has dramatically raised scores on critical thinking tests, and report on recent projects at his Institute.

RALPH H. JOHNSON or J. ANTHONY BLAIR. As co-editors of the journal INFORMAL LOGIC they will be able to give us an overview of what informal logic has accomplished in the recent past. As co-authors of Logical Self-Defence (1983) they will discuss what the ideal course on informal logic or practical reasoning would contain.
PHILIP PECORINO. Director of Critical Thinking Workshops for the Community College Humanities Association and the American Association of Philosophy Teachers (of which he is currently president), he will demonstrate with examples how an informal logician analyzes an argument: the techniques employed, the factors considered, and evaluating the argument.

A number of workshops are planned to treat specific topics for smaller groups. Some will run concurrently. Among the topics we hope to treat are: a survey and critique of currently available critical thinking tests; critical thinking material for primary and secondary school and how to use it; problems of and strategies for getting critical thinking into the curriculum; problems that arise in informal argument analysis and how to deal with them.

The conference will wind up with a panel discussion. Each main speaker will be asked to address any important points he feels have received inadequate coverage.

Ample opportunity will be provided for those attending the conference to ask questions and provide input: after each presentation, at the workshops, and at the panel discussion.

With the cooperation of publishers, we hope to get a good range of commercially available teaching material for critical thinking and informal logic on display. Material important to the presentations and workshops will be copied for the kits of those attending, so long as it is not restricted by copyright.

This conference is presented under the auspices of the Association for Informal Logic and Critical Thinking, and in conjunction with the annual meeting of the Virginia Humanities Association.

For further information contact:

John Hoaglund Department of Philosophy

Christopher Newport College 50 Shoe Lane

Newport News, VA 23606 